\title{
Characteristics of Carbon Tetrafluoride Plasma Resistance of Various Glasses
}

\author{
Jae Ho Choi****, Yoon Soo Han*, Sung Min Lee*, Hyung Bin Park****, \\ Sung Churl Choi**; and Hyeong Jun Kim**t \\ *Engineering Ceramic Center, Korea Institute of Ceramic Engineering and Technology, Icheon 17303, Korea \\ **Department of Materials Science and Engineering, Hanyang University, Seoul 04763, Korea
}

(Received September 30, 2016; Revised November 7, November 19, November 22, 2016; Accepted November 22, 2016)

\begin{abstract}
Etch rate, surface roughness and microstructure as plasma resistance were evaluated for six kinds of oxide glass with different compositions. Borosilicate glass (BS) was found to be etched at the highest etch rate and zinc aluminum phosphate glass (ZAP) showed a relatively lower etch rate than borosilicate. On the other hand, the etching rate of calcium aluminosilicate glass (CAS) was measured to be similar to that of sintered alumina while yttrium aluminosilicate glass (YAS) showed the lowest etch rate. Such different etch rates by mixture plasma as a function of glass compositions was dependent on whether or not fluoride compounds were formed on glass and sublimated in high vacuum. Especially, in view that $\mathrm{CaF}_{2}$ and $\mathrm{YF}_{3}$ with high sublimation points were formed on the surface of CAS and YAS glasses, both CAS and YAS glasses were considered to be a good candidate for protective coating materials on the damaged polycrystalline ceramics parts in semi-conductor and display processes.
\end{abstract}

Key words : Plasma dry etching, Oxide glass, Microstructure, $\mathrm{CF}_{4}$ plasma

\section{Introduction}

$\mathbf{P}$ lasma dry etching process used mainly for micro patterning in semiconductor processes based on Silicon or aluminum are known to have high etching selectivity due to anisotropic etching. ${ }^{1)}$ Owing to this process, micro-patterning was made possible, enabling miniaturization of all electromagnetic devices currently used by us. ${ }^{2-4)}$ Meanwhile, in the recent times where the width of micro patterns has been reduced to the level of $10 \mathrm{~nm}$, removal of contaminants such as particles produced during semiconductor processes became important. In particular, polycrystalline sintered alumina mainly with coating of $\mathrm{Y}_{2} \mathrm{O}_{3}$ having good plasma resistant characteristics has been used as an inside lining material for the semiconductor equipment where plasma etching is implemented. ${ }^{5-9)}$ Surface damages as well as fluoridation are produced in the lining material as a result of repeated plasma etching over a long time. Surface damages and fluoride products are known to induce direct problems where nano- to micron-size particles are dropped off of the ceramic lining material during long-time process, contaminating wafers. ${ }^{10)}$

Since the production costs are excessively increased if the ceramic lining material is consumed as a disposable material, the parts employed for semiconductor processing equipment are being recycled after cleaning. For cleaning of the

${ }^{\dagger}$ Corresponding author: Hyeong-Jun Kim

E-mail : goldbud@kicet.re.kr

Tel : +82-55-792-2414 Fax : +82-55-792-2419 contaminated ceramic lining materials, acids such as nitric acid or sulfuric acid have been used to this process. ${ }^{11,12)}$ As shown in Fig. 1, since alumina with the surface cleaned by acids has roughened surfaces accompanied by exposure of internal pores, considerable amounts of time are required upon application of the recycled item as a result of the acid treated $\mathrm{Al}_{2} \mathrm{O}_{3}$ inducing problems such as particle contamination in semiconductor processes. Namely, in application of the recycled ceramic lining material to processes, there is an initial particle problem which is different from plasma corrosion and occurrence of contaminating particles produced upon long-term use. When a new ceramic lining

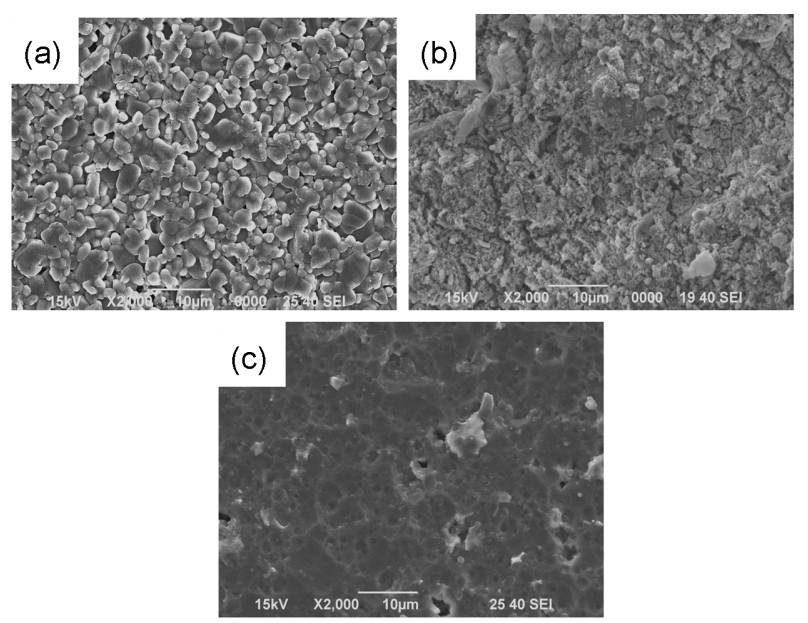

Fig. 1. Microstructures of polycrystalline sintered alumina, (a) origin (b) acid treated and (c) plasma etched. 
material is mounted in semiconductor and display processes, similar problems are also known to occur although the time is short. To suppress such initial particles and outgassing, plasma resistant characteristics have been evaluated for the glass materials having diversified characteristics per composition.

Lee et al have attempted development of materials which not only have permeability but also excellent plasma resistant characteristics by using glasses containing rare earth elements as a material to substitute for quartz or sapphire employed for the window glass in plasma equipment. ${ }^{13)}$ Although plasma resistant characteristics were affirmed for the rare earth-containing glasses, there existed problems of having disadvantages such as expensive raw material prices of rare earth and high manufacturing temperature of $1700^{\circ} \mathrm{C}$ required.

In the present study, plasma resistant characteristics for $\mathrm{CF}_{4} / \mathrm{O}_{2} / \mathrm{Ar}$ mixture plasma have been evaluated for the object of several glasses which are already known to be resistant to hydrofluoric acid or chemicals. Also, plasma resistant characteristics have been comparatively evaluated by selecting zinc aluminum phosphate glass based on consideration of plasma resistant characteristics and thermal expansion coefficient, alkali-free aluminosilicate glass, boric acid glass having chemical stability and $\mathrm{Y}_{2} \mathrm{O}_{3}$-containing yttrium aluminosilicate system known to have high plasma resistant characteristics as the glass material to be coated onto the damaged alumina surface. ${ }^{14-16)}$

\section{Experimental Procedure}

Compositions of the glasses as the object of the present experiment are summarized in Table 1 . As the raw materials for the glass prepared by melting method, $\mathrm{SiO}_{2}, \mathrm{Al}(\mathrm{OH})_{3}$, $\mathrm{ZnO}, \mathrm{P}_{2} \mathrm{O}_{5}$ (99\%, DAEJUNG, Korea) and $\mathrm{Y}_{2} \mathrm{O}_{3}(99.9 \%$, KOJUNDO, Japan) were selected, and commercial borosilicate and glass composition based on calcium aluminosilicate being applied to LCD panel were used for the compositions of BS and CAS, respectively. The samples of $50 \mathrm{~g}$ each per composition were mixed by using a 3-dimensional mixer at $50 \mathrm{rpm}$ for $3 \mathrm{~h}$ to homogenize the composition. Subse-

Table 1. Chemical Compositions of Various Glasses (wt. \%)

\begin{tabular}{ccccccc}
\hline Elements & BS $^{*}$ & CAS $^{*}$ & ZAP1 & ZAP2 & YAS1 & YAS2 \\
\hline $\mathrm{SiO}_{2}$ & 80.5 & 59.7 & & 2 & 30 & 25 \\
$\mathrm{Al}_{2} \mathrm{O}_{3}$ & 2.92 & 16.4 & 18 & 16.4 & 35 & 20 \\
$\mathrm{~B}_{2} \mathrm{O}_{3}$ & 12.2 & 10.3 & & & & \\
$\mathrm{Na}_{2} \mathrm{O}$ & 3.42 & & & & & \\
$\mathrm{CaO}$ & & 8.12 & & & & \\
$\mathrm{SrO}$ & & 4.32 & & & & \\
$\mathrm{P}_{2} \mathrm{O}_{5}$ & & & 72 & 68.4 & & \\
$\mathrm{ZnO}$ & & & 10 & 13.1 & & \\
$\mathrm{Y}_{2} \mathrm{O}_{3}$ & & & & & 35 & 55 \\
\hline
\end{tabular}

* ICP analysis results quently, heat treatment was conducted in a Rh-Pt crucible at a heating rate of $10^{\circ} \mathrm{C} / \mathrm{min}$ for holding at $1600^{\circ} \mathrm{C}$ for $2 \mathrm{~h}$ using an electric furnace of oxidizing atmosphere. After undergoing melting process, the molten body was cooled by air cooling method for vitrification at room temperature. Thermal stress produced in the glass during cooling process for vitrification was relieved through annealing for $2 \mathrm{~h}$ at a temperature higher by $50^{\circ} \mathrm{C}$ than the glass transition temperature measured per specimen. To determine vitrification status, X-ray diffractometer (DMAX-2500, Rigaku, Japan) was employed.

Thus-produced glass specimens were made into the size of $10 \times 10 \times 1 \mathrm{~mm}^{3}$ in length $\mathrm{x}$ width $\mathrm{x}$ height for plasma etching test, and mirror polished to have the surface roughness $\left(R_{a}\right)$ of less than $0.05 \mu \mathrm{m}$ for uniform etching. The prepared specimens were then placed on a 6 -inch Si wafer and subjected to masking processing with Kapton tape on them. For masking processing, 3 layers were overlapped on the tape at an interval between tapes of about $1 \mathrm{~mm}$. To compare plasma resistant characteristics as a function of glass compositions with that for the material used in the past, alumina was employed. Plasma etching experiments were conducted by using a polymer etcher(TCP-9400DFM, Lam Research, USA) in the clean room. Detailed plasma etching conditions are shown in Table 2.

To evaluate plasma resistant characteristics, etching rates were measured for the object of specimens with plasma etching reaction implemented. Here, a mean step for etching rates was obtained by repeated measurements for 5 times by using Alpha Step (Surfcorder ET 3000, Kosaka Lab, Japan), followed by comparative analysis of etch rates per specimen by using an error bar chart for mean values and deviations. In addition, not only etching rates but also surface roughness after reaction to plasma etching was shown by the same equipment. Also, to check for surface state of the etched parts and reaction products between plasma and for glass composition components or contaminants such as particles, microstructures were observed by using scanning electron microscopy (JEOL, JSM-6701F, Japan). For the composition analysis of commercial glass compositions, ICP-OES (OPTIMA 5300 DV, PERKIN-ELMER, USA) and XRF (ZSX Primus, RIGAKU, Japan) were employed.

Table 2. Conditions for Plasma Etching

\begin{tabular}{cc}
\hline Parameter & Condition \\
\hline RF power [W] & 600 \\
RF power, bias [W] & 200 \\
$\mathrm{CF}_{4}[\mathrm{SCCM}]$ & 30 \\
$\mathrm{Ar}[\mathrm{SCCM}]$ & 5 \\
$\mathrm{O}_{2}[\mathrm{SCCM}]$ & 10 \\
Pressure [mTorr] & 30 \\
Time [min.] & 60 \\
\hline
\end{tabular}




\section{Results and Discussion}

In Fig. 2, a schematic diagram for plasma reaction and etching process occurring in the material is summarized. ${ }^{17)}$ In the etching with the use of plasma, particles ionized by granting electrical energy in the state of neutral gas are used. And, by granting electrical energy to $\mathrm{CF}_{4}, \mathrm{O}_{2}$ and $\mathrm{Ar}$ neutral gas, the ionization processes can be shown approximately by the equations (1), (2) and (3), respectively. ${ }^{18)}$

$$
\begin{aligned}
& \mathrm{CF}_{4}+\mathrm{e}^{-} \rightarrow \mathrm{CF}_{3}^{+}+\mathrm{F}^{*}+2 \mathrm{e}^{-} \\
& \mathrm{CF}_{4}+\mathrm{O}_{2} \rightarrow \mathrm{CO}_{2}+2 \mathrm{~F}_{2} \\
& \mathrm{Ar}+\mathrm{e}^{-} \rightarrow \mathrm{Ar}^{+}+2 \mathrm{e}^{-}
\end{aligned}
$$

Through the ionization to neutral gas, fluorine radicals and $\mathrm{Ar}^{+}$ions are mainly formed through the above reactions. In plasma etching process, physical ion collisions within the sheath potential through sputtering of $\mathrm{Ar}^{+}$ions and chemical reaction between fluorine radical and the etched material take place on the surface. After generation of reaction products due to reaction between material surface and plasma through this process, desorption reaction from the substrate occurs. ${ }^{19,20)}$

Etch rates for the compositions of borosilicate (BS) and calcium aluminosilicate (CAS), the glass compositions of zinc aluminum phosphate (ZAP) system and yttrium aluminosilicate (YAS), along with polycrystalline alumina currently used for a plasma resistant material as the reference materials for comparison with these are shown in Fig. 3. Etch rates of the glasses having BS, ZAP1, and ZAP2 compositions were $268 \mathrm{~nm} / \mathrm{min}, 164 \mathrm{~nm} / \mathrm{min}$, and $145 \mathrm{~nm} / \mathrm{min}$, respectively, being relatively higher than the etch rate for polycrystalline alumina of $57 \mathrm{~nm} / \mathrm{min}$. On the other hand, etch rates of the glasses having CAS, YAS1, and YAS2 compositions were $64 \mathrm{~nm} / \mathrm{min}, 23 \mathrm{~nm} / \mathrm{min}$, and $14 \mathrm{~nm} / \mathrm{min}$, respectively, showing similar or lower etch rates compared with that for polycrystalline alumina. Namely, with alu-
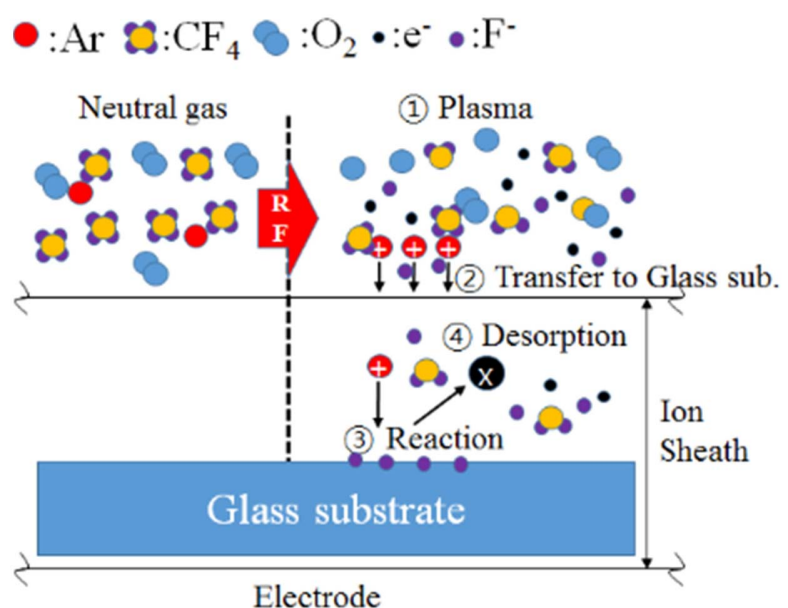

Fig. 2. Scheme for reactive ion plasma etching process on the surface. ${ }^{17)}$ mina as reference, etch rates for CAS and YAS-based compositions were measured to be similar or lower, whereas those for BS and ZAP-based compositions were measured to be relatively much higher. As a reaction product due to chemical reaction between glass composition on the surface and fluorine radical during plasma etching process, fluoride compounds were formed. Considering Table 3 for summary of sublimation points for fluorides per element, all sublimation point points for boron, silica, and phosphate as the major components for BS and ZAP-based compositions were lower than $-80^{\circ} \mathrm{C}$, having volatilization characteristics due to fluoride reaction, whereas all sublimation points for the fluorides of yttrium, calcium, and aluminum among the compositions included in CAS and YAS had values higher than $1,200^{\circ} \mathrm{C}^{21,22)}$ The cause for showing different etch rates per composition is attributed to the sublimation temperature as fluoride compounds were formed within the glass compositions due to chemical reaction in the plasma etching process.

Although ZAP-based composition was expected to have excellent plasma resistant characteristics as it was known to have high resistance to hydrofluoric acid, a higher etch rate than that for alumina was measured. Etching by not

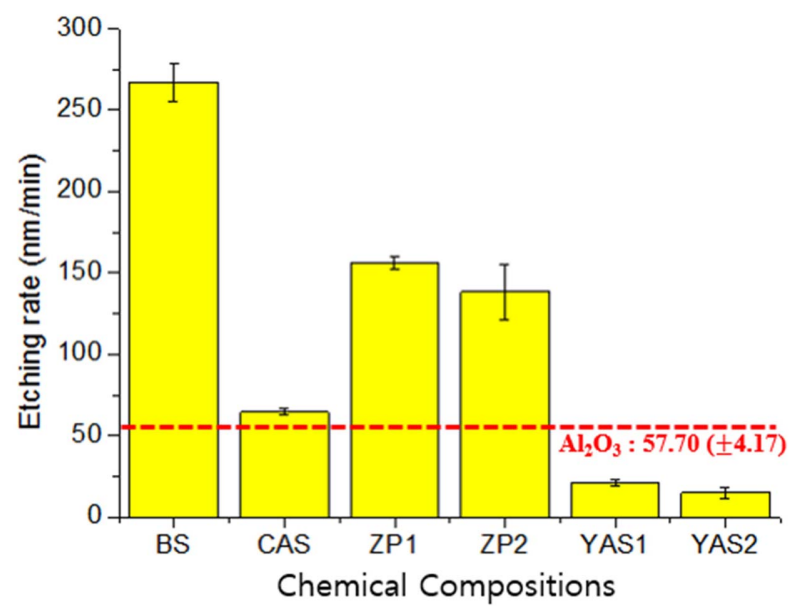

Fig. 3. Etch rates for various glasses compositions as compared with polycrystalline sintered alumina.

Table 3. Sublimation Points for Each Fluoride Compound ${ }^{22)}$

\begin{tabular}{cc}
\hline Fluoride compound & Temperature $\left({ }^{\circ} \mathrm{C}\right)$ \\
\hline $\mathrm{SiF}_{4}$ & -86 \\
$\mathrm{BF}_{3}$ & -100 \\
$\mathrm{PF}_{3}$ & -101 \\
$\mathrm{AlF}_{3}$ & 1,275 \\
$\mathrm{ZnF}_{2}$ & 1,500 \\
$\mathrm{NaF}$ & 1,704 \\
$\mathrm{YF}_{3}$ & 2,230 \\
$\mathrm{BaF}_{2}$ & 2,260 \\
$\mathrm{SrF}_{2}$ & 2,460 \\
$\mathrm{CaF}_{2}$ & 2,533 \\
\hline
\end{tabular}


only fluorine radical but also ionized $\mathrm{Ar}^{+}$makes contribution to plasma etching. Hence, resistance to physical etching by $\mathrm{Ar}^{+}$as well as chemical reaction due to fluorine should be considered for plasma resistant materials. Shin et al considered the relationships between glass transition temperature $\left(\mathrm{T}_{\mathrm{g}}\right)$ and weak interatomic binding force, ${ }^{23)}$ while Ojovan stated that $\mathrm{T}_{\mathrm{g}}$ was a temperature range in which stable arrangement of atoms was realized as interatomic inter-diffusion took place in the relevant temperature range and that interatomic bonding was strong if the transition temperature was high. ${ }^{24)}$ The cause for the high etch rate with ZAP is considered attributable to not only volatile characteristics of $\mathrm{PF}_{3}$ compound as the major component for phosphate but also low interatomic bonding energy.

According to the article published by Kim on plasma resistant characteristics as a function of plasma etching variables for SiC material, etch rates showed a relationship of being proportional to surface roughness and DC bias. ${ }^{25)}$ Fig. 4 shows surface roughness values for the surfaces of alumina and representative specimens per composition after plasma etching. For CAS, the value of $1.24 \mu \mathrm{m}$ was measured despite a relatively low etch rate compared with other glass compositions, which represents the highest surface roughness value among all glass compositions. While the rather low surface roughness of $0.57 \mu \mathrm{m}$ was measured for ZAP2 in comparison with CAS, it showed a high surface roughness when compared with that for YAS-based glass composition. And, the value for YAS2 of $0.15 \mu \mathrm{m}$ showed not only the lowest etch rate, but also allowed affirmation of the smoothest surface of all glass compositions.

Figure 5 shows microstructures observed to check for the causes for different surface roughness values per composition, surface state and reaction products after etching, and contaminants in the form such as particles observed in alumina. In CAS composition, the reaction products of $0.5 \sim$ $3 \mu \mathrm{m}$ in size were observed, due to which the highest surface roughness is considered to have been measured among the

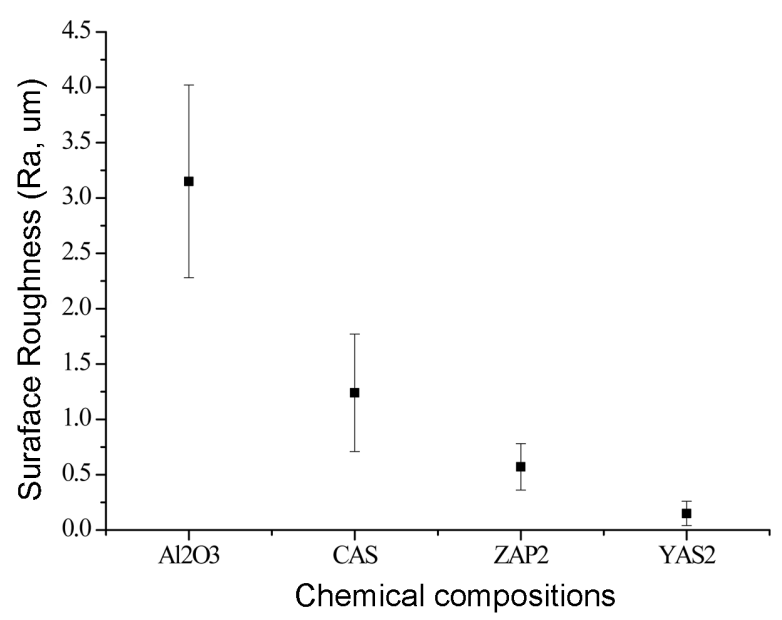

Fig. 4. Surface profile of alumina and glasses after fluorine plasma etching process. glass compositions. Although BS was expected to show a high etch rate along with a surface microstructure with clear occurrence of etching having no reaction products due to low surface roughness, reaction products having diversified forms were observed with a nano size of less than 0.5 $\mu \mathrm{m}$. And, in general, the etching process not only removes surface materials but also changes surface morphologies. ZAP 1 and 2 showed a morphology such as glassy surface with microstructural shape changed due to etching by hydrofluoric acid solution. ${ }^{26,27)}$ This shows clear occurrence of inward etching, and is considered to represent the surface etched as phosphate composition in ZAP was volatilized due to reaction with fluorine. Lastly, although the parts expected as damage produced during fabrication process were observed in YAS1 and YAS2, no other phenomenon due to plasma etching was discovered, allowing affirmation of excellent etching resistance for the present material.

Figure 6 shows the EDS analysis results for chemical compositions of the reaction products observed in CAS and BS microstructures. For the reaction products of $0.5 \sim 3 \mu \mathrm{m}$ in size observed from the microstructure of CAS samples, clear increase in carbon and fluorine composition which were not included in the glass can be affirmed. And, carbon and fluorine compositions were also affirmed according to the EDS analysis results for the reaction products which were more clearly observed than in BS. As more than 90 wt.\% of BS consists of $\mathrm{SiO}_{2}$ and $\mathrm{B}_{2} \mathrm{O}_{3}$ with the balance being comprised of $\mathrm{Na}_{2} \mathrm{O}$ and $\mathrm{Al}_{2} \mathrm{O}_{3}$, fluoride of low sublimation can be generated. According to Aoki, boron trifluoride produced by reaction between boron element and $\mathrm{CF}_{4}$ was
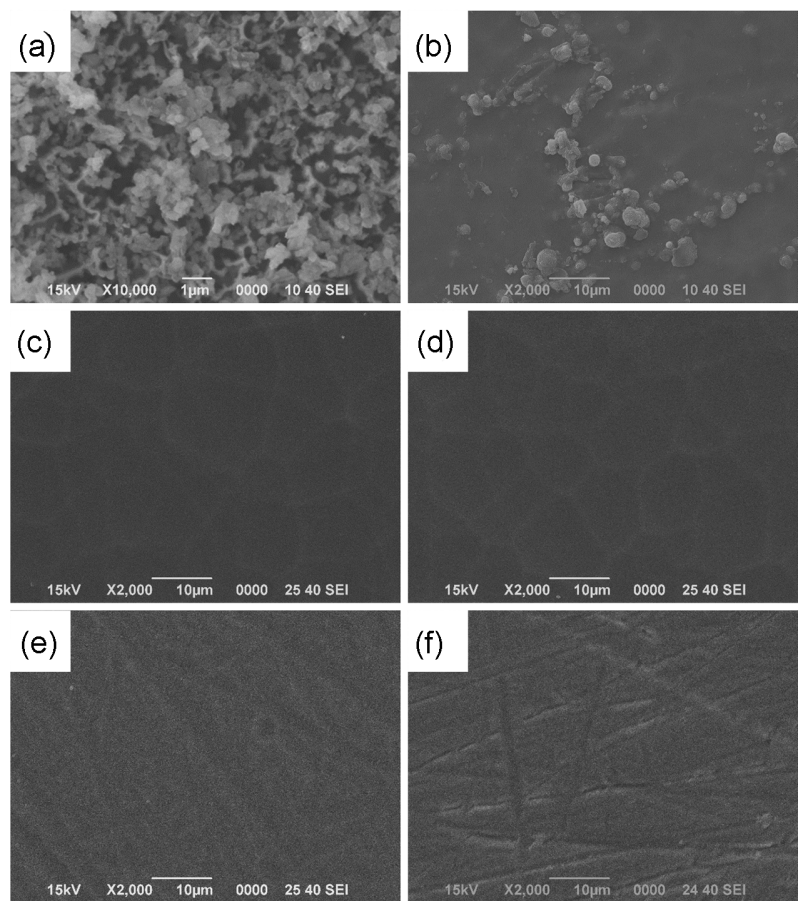

Fig. 5. Microstructures of glasses after reactive ion plasma etching process; (a) BS, (b) CAS, (c) ZAP1, (d) ZAP2, (e) YAS1, and (f) YAS2. 

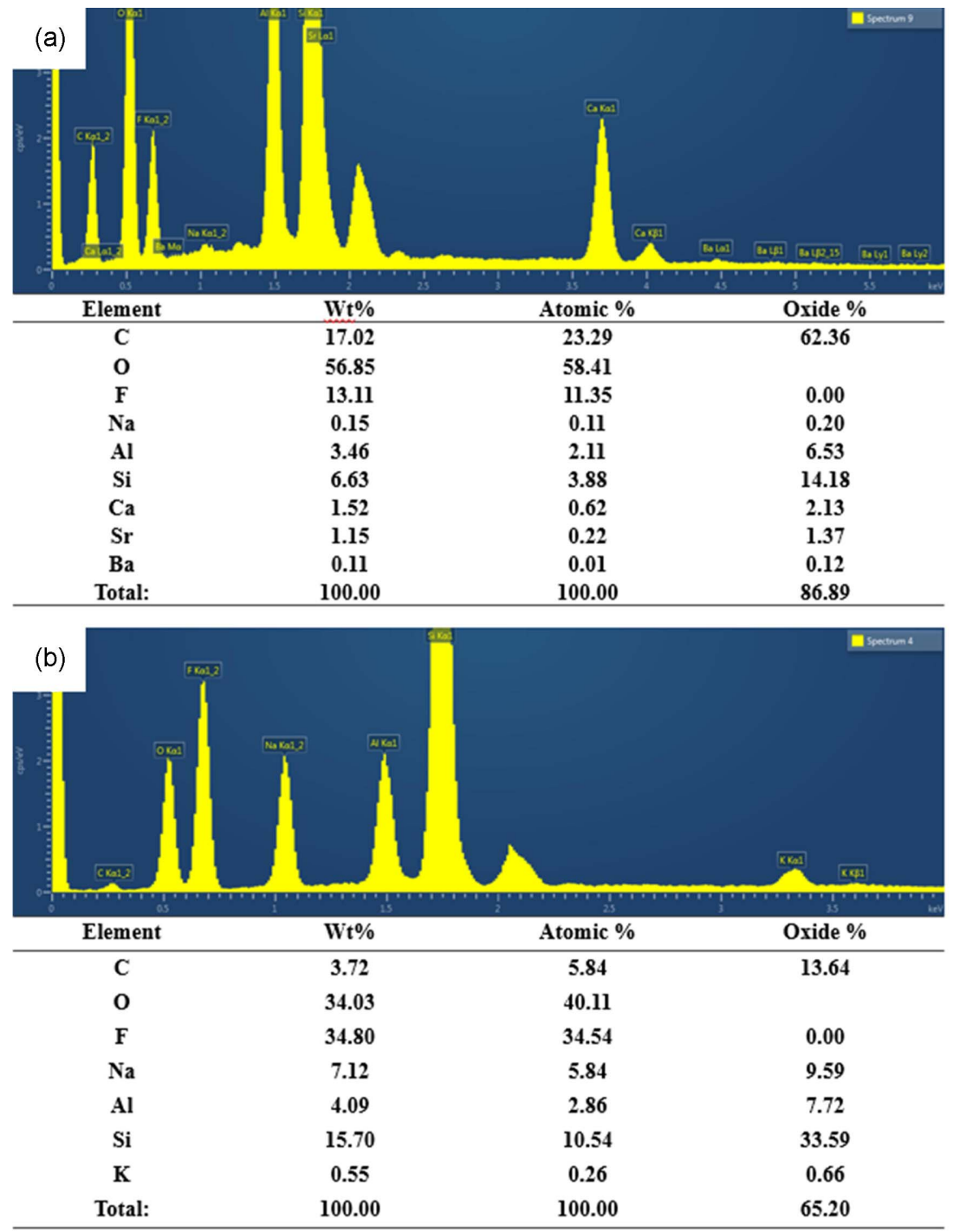

Fig. 6. EDS analysis for byproducts of (a) CAS and (b) BS.

reported to be sublimated accompanied by occurrence of byproducts, which can be expressed by the equation (4). ${ }^{28)}$ Therefore, the byproducts observed in the microstructure after corrosion test of the glasses with BS and CAS compositions are considered to remain in the fluorides such as $\mathrm{NaF}$, $\mathrm{AlF}_{3}$, etc. together with the reaction products of $\mathrm{CF}_{\mathrm{x}}$ polymer type due to the reaction of equation (4).

$$
\mathrm{B}+\mathrm{CF}_{4} \rightarrow \mathrm{BF}_{3} \uparrow+\mathrm{CF}_{\mathrm{x}} \text { (polymer) }
$$

CAS composition has a chemical composition where $\mathrm{CaO}$ and $\mathrm{B}_{2} \mathrm{O}_{3}$ were added to aluminosilicate base. $10 \mathrm{wt} . \%$ of $\mathrm{B}_{2} \mathrm{O}_{3}$ having volatilization characteristics as a function of Fluoride was added, and $\mathrm{CaO}$ showed an etch rate on the level similar to that of alumina although only $8 \%$ of the total was added. This may be caused by a relatively low $\mathrm{SiO}_{2}$ content and a high $\mathrm{Al}_{2} \mathrm{O}_{3}$ content. In the future, plasma resistant characteristics for fluorine plasma need to be evaluated for the object of glasses with $\mathrm{CaO}$ being mixed as the main composition.

Glass is a mixture made of mixing diversified compositions having different properties each elements. Interior of YAS has oxygen bridges formed through ionic bonding and covalent boding of $\mathrm{SiO}_{2}, \mathrm{Al}_{2} \mathrm{O}_{3}$ and $\mathrm{Y}_{2} \mathrm{O}_{3}$ as the glass former and the intermediate. Whereas the glass surface is volatilized due to a low sublimation point in the case of $\mathrm{SiO}_{2}$ as a result of chemical reaction with fluorine radical in plasma etching process, $\mathrm{Y}_{2} \mathrm{O}_{3}$ and $\mathrm{Al}_{2} \mathrm{O}_{3}$ having sublimation points higher than $1,200^{\circ} \mathrm{C}$ are expected to exist in the surface in the state of fluoride compounds such as $\mathrm{AlOF}$ and $\mathrm{AlF}_{3}$ which were not volatilized by reaction. Simple reaction equations for the above reaction can be expressed by (5) and (6).

$$
\begin{aligned}
& \mathrm{SiO}_{2}(\mathrm{~s})+2 \mathrm{~F}_{2}(\mathrm{~g}) \rightarrow \mathrm{SiF}_{4}(\mathrm{~g}) \uparrow+\mathrm{O}_{2}(\mathrm{~g}) \\
& \mathrm{Al}_{2} \mathrm{O}_{3}(\mathrm{~s})+3 \mathrm{~F}_{2} \rightarrow 2 \mathrm{AlF}_{3}(\mathrm{~s})+2 / 3 \mathrm{O}_{2}(\mathrm{~g})
\end{aligned}
$$

Since the reactions on the glass surface between glass 
composition and plasma are more complicated than the reaction equations (5) and (6), accurate reactions of the formed products such as fluoride compounds after surface reaction need to be affirmed. For this purpose, in-depth studies will be conducted in the future with application of analysis techniques such as XPS and FT-IR which would allow identification of binding energy on an atomic scale, relative ratio between elements, type of binding and accurate molecular structures such as functional group for the products after reaction.

\section{Conclusions}

In the present study, plasma resistant characteristics were evaluated by comparing various oxide glasses and polycrystalline sintered alumina for dry etching by mixture plasma of $\mathrm{CF}_{4} / \mathrm{O}_{2} / \mathrm{Ar}$. In YAS series, the lowest etch rate of $14 \mathrm{~nm} / \mathrm{min}$ and flat surface with existed scratch could be affirmed in YAS2 composition having higher yttrium content. In addition, the etch rate of $64 \mathrm{~nm} / \mathrm{min}$ similar to that for alumina could also be affirmed in CAS composition. Based on this result, it can be seen that plasma resistant characteristics to fluoride plasma are increased if yttrium element is added to the glasses of an amorphous structure. On the other hand, boron, phosphate and silicon elements contained in the glass were volatile, showing high etch rates as sublimation points of all fluoride reaction products had values lower than $-80^{\circ} \mathrm{C}$.

In general, it was affirmed that glass composition with high resistance to hydrofluoric acid or chemicals did not exhibit excellent plasma resistant characteristics. Differences in the component elements added to glass composition were affirmed to show different plasma resistant characteristics. Namely, it could be affirmed that glasses containing the elements capable of forming fluorides having a high sublimation point with fluorine radical among glass compositions produced durability for $\mathrm{CF}_{4} / \mathrm{O}_{2} / \mathrm{Ar}$ plasma employed in semiconductor or display process.

\section{REFERENCES}

1. S. Aachboun and P. Ranson, "Deep Anisotropic Etching of Silicon,” J. Vac. Sci. Technol. A, 17 2270-73 (1999).

2. G. S. Oehrlein and Y. Kurogi, "Sidewall Surface Chemistry in Directional Etching Processes," Mater. Sci. Eng. R, 24 [4] 153-83 (1998).

3. C. Cardinaud, M. C. Peignon, and P. Y. Tessier, "Plasma Etching: Principles, Mechanisms, Application to Micro- and Nano-technologies," Appl. Surf. Sci., 164 [1-4] 72-83 (2000).

4. R. A. Gottscho, C. W. Jurgensen, and D. J. Vitkavage, "Microscopic Uniformity in Plasma Etching," J. Vac. Sci. Technol. B, 10 2133-47 (1992).

5. N. Ito, T. Moriya, F. Uesugi, M. Matsumoto, S. Liu, and Y. Kitayama, "Reduction of Particle Contamination in Plasma-Etching Equipment by Dehydration of Chamber Wall," Jap. J. Appl. Phys., 47 3630-34 (2008).

6. D. M. Kim, K. B. Kim, S. Yoon, Y. S. Oh, H. T. Kim, and S.
M. Lee, "Effects of Artificial Pores and Purity on the Erosion Behaviors of Polycrystalline $\mathrm{Al}_{2} \mathrm{O}_{3}$ Ceramics under Fluorine Plasma," J. Ceram. Soc. Jpn., 117 863-67 (2009).

7. R. Ramos, G. Cunge, B. Pelissier, and O. Joubert, "Cleaning Aluminum Fluoride Coatings from Plasma Reactor Walls in $\mathrm{SiCl}_{4} / \mathrm{Cl}_{2}$ Plasmas," Plasma Sources Sci. Technol., 16 [4] 711-15 (2007).

8. A.Miyazaki, K. Morita, S. Nagasaka, and S. Moriya, "Plasma-resistant Member and Plasma Treatment Apparatus Using the Same", US patent 6834613 (August 24, 1999).

9. K. Morita, H. Ueno and H. Murayama, "Plasma-resistant Articles and Production Method Thereof", US patent 6933254 (November 19, 2002).

10. K. Miwa, T. Sawai, M. Aoyama, F. Inoue, A. Oikawa, and K. Imaoka, "Particle Reduction using $\mathrm{Y}_{2} \mathrm{O}_{3}$ Material in an Etching Tool,"; pp. 479-482 in IEEE Int. Symp. Semicond. Manuf. Confer. Proc., San Jose, CA, 2005.

11. B. R. Chrcanovic, N. L. C. Leão, and M. D. Martins, "Influence of Different Acid Etchings on the Superficial Characteristics of Ti Sandblasted with $\mathrm{Al}_{2} \mathrm{O}_{3}$, Mater. Res., 16 [5] 1006-1014 (2013).

12. J. Q. Dai, Y. H. Z. P. Xie, X. L. Xu, and J. L. Yang, "Effect of Acid Cleaning and Calcination on Rheological Properties of Concentrated Aqueous Suspensions of Silicon Nitride Powder," J. Am. Ceram. Soc., 85 [2] 293-98 (2002).

13. J. Lee, D. Kim, S. Lee, and H. Kim, "Effect of Rare-earth Elements on the Plasma Etching Behavior of the RE-SiAl-O Glasses," J. Non-Cryst. Solids, 358 898-902 (2012).

14.Z. Chabbou1 and S. Aqdim, "Chemical Durability and Structural Proprieties of the Vitreous Part of the System xCaO-(40-x)ZnO- $15 \mathrm{Na}_{2} \mathrm{O}-45 \mathrm{P}_{2} \mathrm{O}_{5}$, Adv. Mater. Phys. Chem., 4 [10] 179-86 (2014).

15. R. J. Eagan and J. C. Swearekgen, "Effect of Composition on the Mechanical Properties of Aluminosilicate and Borosilicate Glasses," J. Am. Ceram. Soc., 61 27-30 (1978).

16. M. J. Hyatt and D. E. Day, "Glass Properties in the YttriaAlumina-Silica System,” J. Am. Ceram. Soc., 70 [10] C28387 (1987).

17. K. Nojiri, Dry Etching Technology for Semiconductors; pp. 16, Springer, Switzerland, 2015.

18. D. M. Manos and D. L. Flamm, Plasma etching an introduction; pp. 129-30, Academic press, INC., 1989.

19. D. L. Flamm, V. M. Donnelly, and D. E. Ibbotson, "Basic Chemistry and Mechanisms of Plasma Etching," J. Vac. Sci. Technol. B, 1 23-30 (1983)

20. D. Shamiryan, M. Baklanov, M. Claes, W. Boullart, and V. Paraschiv, "Selective Removal of High-k Gate Dielectrics," Chem. Eng. Commun., 196 [12] 1475-535 (2009).

21. J. D. B. Bradley, F. Ay, K. Worhoff, and M. Pollnau, "Fabrication of Low-loss Channel Waveguides in $\mathrm{Al}_{2} \mathrm{O}_{3}$ and $\mathrm{Y}_{2} \mathrm{O}_{3}$ Layers by Inductively Coupled Plasma Reactive Ion Etching," Appl. Phys. B, 89 311-18 (2007).

22. P. Patnaik, Handbook of Inorganic Chemicals; pp. 304-6, McGraw-Hill, 2002.

23. P. Y. Shin and T. S. Chin, "Preparation of Lead-free Phosphate Glasses with Low $\mathrm{T}_{\mathrm{g}}$ and Excellent Chemical Durability," J. Mater. Sci. Lett., 20 1811-13 (2001).

24. M. I. Ojovan, "Configurons: Thermodynamic Parameters 
and Symmetry Changes at Glass Transition," Entropy, 10 334-64 (2008).

25. B. W. Kim and B. T. Lee, "Relationships Between Etch Rate and Roughness of Plasma Etched Surface," IEEE Trans. Plasma Sci., 30 [5] 2074-77 (2002).

26. S. T. Tos and J. A. Pask, "Reaction of Glasses with Hydrofluoric Acid Solution,” J. Am. Ceram. Soc., 65 [7] 360-62 (1982).
27. G. A. C. M. Spierings, "Wet Chemical Etching of Silicate Glasses in Hydrofluoric Acid Based Solutions," J. Mat. Sci., 28 6261-73 (1993).

28. H. Aoki, S. Tokuyama, T. Sasada, D. Watanabe, M. K. Mazumder, C. Kimura, and T. Sugino, "Dry Etching Properties of Boron Carbon Nitride (BCN) Films Using Carbon Fluoride Gas," Diam. Relat. Mater., 17 1800-4 (2008). 